One of many strengths of Thomson's research is that he makes explicit that which we have intuited, observed, and experienced. First, he analyses those specific socio-economic and political factors which have influenced legislation such as the Abortion Act and the Human Fertilisation and Embryology Act. For example, he questions how conceptions of the aborting woman as "angel or witch, wearied mother or feckless girl, tired housewife or tart" impacted on abortion policies (page 69). Second, he scrutinises industrial fetal policies which maintain traditional sexual divisions. Third, he considers how the image and the concept of the fetus has grown in the abortion debate, eclipsing the primacy of the woman's status.

A few examples will demonstrate the flavour and complexity of Thomson's analysis. The creative references include Peter Greenaway's film The Life of Macon, in which Greenaway reflected upon the sacred and profane power of the iconography of the fetus/ child. Margaret Atwood's novel, The Handmaid's Tale, is mined for insights regarding the "fable warning of the present day objectification of woman as reproducers", which is relevant to the industrial fetal protection analysis. The "monstrous" conception of the female body, as imagined in Mary Shelley's Frankenstein, has contemporary resonance for Thomson: "The female is an object both of desire and of fear, sexual fascination and horror. These associations, of desire and fear, of the monstrous and the necrophilial, have, importantly, been clearly retained and developed within the Frankenstein of film" (page 174).

Thus, Thomson draws from vastly diverse disciplines to illustrate his central thesis; this thesis is relevant for those who contemplate medical ethics because we must acknowledge the powerful ways in which gender influences new reproductive technology and the intervention in the female body more generally.

Thomson provides a balanced analytical approach, which is comprehensively referenced, finely nuanced and eclectic. Consequently, this publication is informative and provocative. Thomson's research is entirely relevant to those medical and legal professionals who rise to the challenge of reflecting upon the social consequences of their own practices and professions.

KATE DIESFELD Kent Law School, University of Kent at Canterbury

\section{Reforming Healthcare by Consent: Involving Those who Matter}

\author{
Edited by Tom Ling, Abingdon, \\ Radcliffe Medical Press, 1999, \\ 235 pages, £22.50.
}

This book is a collection of essays reflecting on the influence and engagement of users in health care development. The word collection feels appropriate here as the essays are very disparate, and without connection, cross-referencing or theming. There are very short chapters (a delightful one by Roy Lilley is only three pages long) but others are many pages long with few subheadings, diagrams or pictures to relieve the reader. (I have to admit like Alice to not enjoying books that "have no pictures or conversation".)

Such is the speed of change in the National Health Service (NHS) that any publication will inevitably be out of date by the time it is published. The introduction acknowledges that the creation of the book has taken a number of years. This is very evident. Some chapters were written after the changes to the NHS were announced in December 1997, but others seem to have been written long before that. We are embarking on a radical change to the NHS and the message from the book is that health care consumers must influence the shape of services. Although the book was published in 1999 and therefore the demise of general practitioner (GP) fundholding was only weeks away, the mention in the first chapter both of fundholding and family health services authorities (which were written out of the NHS several years ago), and only a passing reference to primary care groups in the rest of the book, detracts from that message.

This book does not fully make the case for the ethical imperative of consumer involvement in every corner of health care policy and practice. Many areas are tackled but there are gaps. There is a large endeavour to involve consumers in the whole research agenda, still in its infancy, but this is not mentioned. Nor is the importance of involving consumers in quality (nowhere are the words "clinical governance" mentioned). The tumultuous fallout of the General Medical Council (GMC) hearing of the Bristol doctors is touched on presciently by a couple of authors. But the implica- tions for the relationship between professional and user is not addressed, and there is no mention of the Bristol hearing or its repercussions. It would have also been valuable to have had an international perspective on what is a global issue.

Having said that, there are some wonderful chapters that absorb, challenge and inform. I found the chapters on the role of the pharmaceutical industry and its relationship to the public, Let the industry talk to patients, and the chapter on the lack of consumer involvement in information technology (IT), particularly thoughtprovoking. But with the rather unsystematic approach to a diverse range of issues, you will have to dig deep for gems.

ALISON HILL

Public Health Resource Unit, Oxford

\section{The Birth of Bioethics}

\author{
Albert R Jonsen, New York, Oxford, \\ Oxford University Press, 1998, 431 \\ pages, $£ 37.50$ (hb).
}

What is bioethics? Is it a discipline in its own right or a sub-field of other disciplines such as philosophy, law or theology applied to moral problems in health care? Perhaps the best way to approach this question is to see it as an academic discipline which represents a way of doing ethics somewhere between the logic of moral philosophy and the exigencies of practical policy. Albert Jonsen has written what appears to be the first broad history of bioethics, covering its origins and evolution between 1947 and 1987. According to Jonsen it emerged as a distinct discipline during the 1960s, when various scholars migrated from academic subjects such as law, philosophy and theology, and developed new ways of viewing the traditional ethics associated with medicine. At present bioethics has three professional associations with over 1,000 members and almost 200 centres. Jonsen notes that over 3,500 books and articles on bioethics have been listed. Bioethicists are in great demand by governments and the media, and bioethics commissions and conferences are to be found throughout the world.

In this detailed and widely researched history Jonsen portrays the driving force behind the development of bioethics as the steady accumulation of public concern with the ambiguities generated by scientific develop- 
ments in medicine, where the simplified image of the caring country doctor with his black bag was replaced with images of medical teams employing modern scientific resources in intensive care units and transplant centres. Moral issues concerning benefit and harm, which were once considered obvious and noncontroversial, became challenging when viewed against a social background wherein greater emphasis was placed upon respect for the individual as a decision maker. Thus questions about justice and the meaning of life and death, long debated by lawyers, philosophers and theologians, took on a practical aspect within the context of new scientific medicine.

Jonsen examines the issues which generated most concern in the postwar years, such as human experimentation, genetic engineering, termination of life-sustaining treatment, and problems related to the new reproductive technologies. These topics occupy the five central chapters of the book, where each one is situated in its historic context and its treatment in bioethical discourse is examined. It is worth noting that these historical studies are not confined to the forty years of bioethics which is the intended scope of the book. Jonsen recognises that many of the philosophical and theological problems have a long ancestry and his excursions into their historical origins will be appreciated by the contemporary reader. There is also a wealth of information concerning the early conferences and commissions dealing with bioethical issues, together with the arguments of some of the major figures in bioethics. As a prominent member of the US President's Commission Jonsen is particularly informative with regard to the debates which resulted in several of its influential reports.

Many of Jonsen's historical and ethical surveys testify to the immorality of the unrestrained application of science to medicine throughout this century, from abuses in research on human subjects to the infamous pursuit of eugenics, the early years of organ transplantation, attitudes towards the dying and the dead, and the controversies generated by scientific involvement in human reproduction. The emergence of bioethics is consequently an expression of public concern.

Towards the end of the book there is a chapter which examines bioethics as an academic discipline and the search for a general theory for bioethics; a chapter on bioethics as a form of public discourse which is carried out by many people outside of the academy, and a final chapter which locates the origin and evolution of bioethics in the Americal liberal tradition. By "liberal tradition" Jonsen means the ethos in which the US civil rights movement emerged and the opposition to American involvement in the war in South East Asia, which gave expression to concern for the rights of individuals and a distrust of authority. This would suggest that bioethics is primarily an American phenomenon, and whilst the emergence of bioethics outside the US is covered briefly, that is a subject which lies beyond the scope of this book.

DAVID LAMB

University of Birmingham

\section{Rationing: Talk and Action in Health Care}

\section{Edited by Bill New, London, BMJ \\ Publishing Group, 1997, 261 pages, $£ 25.00$.}

Rationing, a word destined to bring shivers down the spines of our political masters, despite the general agreement of all who work within the National Health Service (NHS) and the vast majority of the public that, however one may choose to label it, the central issue is about how choices are to be made under conditions of scarce resources. The many authors come from within the service or from policy institutes, and include clinicians, economists and analysts. Professional philosophers are less well represented. There is little to be found in the way of underpinning assertions based on ethical theory, and where attempts are made, the results are not altogether successful.

The articles cover the entire range of issues that have attracted the interest of those working in the field. I particularly enjoyed the debate between Alan Williams and John Grimley Evans on age as a criterion for rationing, and between Tony Culyer and John Harris on the objectives of the NHS. By far the most original article, I thought, was that by Len Doyal and Joanna Coast, who discuss the extent to which rationing should be made explicit at the different levels of decision making. It is so much a part of the culture of the NHS that decision making should be explicit, that $\frac{2}{T^{2}}$ counterargument to suggest that plicitness might have a disutility of $\bar{f}$ s own or that it might not best serve the interests and welfare of individ patients was to me quite refreshi民g. Many clinicians have intuitively alwfs believed this and have not be persuaded by the arguments for esplicitness and public participation. They will find some comfort $\mathrm{m}$ tye more formal articulation of their views, not only by . Coast, a heafh economist, but by commentators such as David Mechanic, a sociologist, a David Hunter, a policy analyst, in referenced literature.

The second section of the bod which debates the issues described above, was the most successful aid enjoyable. The first section, said of deal with "the theoretical policy debate", was less successful and in view did not achieve its stated aim. Nevertheless there is much commen sense and realism to be found in Bgll New's chapter, written on behalf of the Rationing Agenda (RAG), and Chris Heginbotham's robust coun@r to the arguments of the idiosyncratic Anti-Rationing Group, in his chapgr on the inevitability of rationing the NHS. I was disappointed to learnthat a consensus from the RAG, that the method of financing the NHS shouifd be based on general taxation, hod emerged without any discussion as $\frac{80}{0}$ the reasons for that consensus, \&r without an ethical dissection of t鹿e benefits and risks of a mixed econowy in the funding of health services. The central importance of equity or faîness as a guiding value in the delivery of health services can be accepted $\overline{\mathrm{B}} \mathrm{y}$ most if not everyone, but there has been little debate as to whether the managed introduction of a privatepublic mix will lead to greater or lesşr degrees of equity in a social environment where greater accessibility fo health information and consumerism predominate, and where technical a scientific developments are likely escalate even further the costs of health care.

In the third section useful summe ries are given of practical attempts 40 apply rationing in real clinical sitie tions. Experiences from other coumtries are always informative, and t䙵e information from both Sweden affd New Zealand proves to be no exce tion. The attempt by David Ebbs a]d his colleagues to provide a framewōpk for rationing in a general practice sefting is a brave attempt, but I am t persuaded that there are no significant 